\title{
Rafael Gutiérrez Girardot y José Luis Romero: historiografía e identidad latinoamericana
}

\author{
Rafael Gutiérrez Girardot and José Luis Romero: \\ historiography and Latin American identity
}

\author{
Rafael Gutierrez Girardot e José Luis Romero: \\ historiografia e identidade Latino-americana
}

Fecha de entrega: 20 de marzo de 2014

Fecha de evaluación: 15 de junio de 2014

Fecha de aprobación: 15 de septiembre de 2014

Por: Damián Pachón Soto*

\section{Resumen}

En este artículo realizo una lectura de la propuesta historiográfica de José Luis Romero y de la "Historia social de la literatura" de Rafael Gutiérrez Girardot, mostrando cómo la primera influye en la segunda, y relacionándolas con el problema de la identidad de América Latina. Se parte de un diagnóstico de la historiografía colombiana del siglo XX y se evidencia la manera como estas dos miradas historiográficas lograron superar las deficiencias de la misma, fundando en nuestro continente una utopía política que aboga por una conciencia de América.

* Candidato a Doctor en Filosofía, por la Universidad Santo Tomás. Profesor Facultad de Filosofía y Letras de la misma universidad. Autor de varios libros, entre ellos, "La concepción de Hispanoamérica en Rafael Gutiérrez Girardot", "La filosofia y las entrañas. El pensar viviente de Maria Zambrano", "Preludios filosóficos a otro mundo posible", "La civilización unidimensional. Actualidad del pensamiento de Herbert Marcuse". Contacto: damianpachon@gmail.com 
Palabras clave: Gutiérrez Girardot, José Luis Romero, historiografía, identidad, utopía, América Latina, filosofía.

\section{Abstract}

This paper made a reading of the historiographical proposal of José Luis Romero and of the "Social history of literature" by Rafael Gutiérrez Girardot, showing how the former influences the latter, and relating them to the problem of identity in Latin America. It starts from a diagnosis of Colombian historiography of the twentieth century and shows how these two historiographical views managed to overcome its shortcomings, founding in our continent a political utopia that advocates for a conscience of America.

Keywords: Gutiérrez Girardot, José Luis Romero, historiography, identity, utopia, Latin America, philosophy.

\section{Resumo}

Neste artigo faço uma leitura da proposta historiográfica de José Luís Romero e da "História Social da Literatura", de Rafael Gutierrez Girardot, mostrando como a primeira influi na segunda, e relacionando-as com o problema da identidade da América Latina. Ela começa com um diagnóstico da historiografia colombiana do século XX e é evidenciando a maneira como estes dois olhares historiográficos conseguem superar as deficiências da mesma, baseando-se em nosso continente uma utopia política que defende uma consciência da América.

Palavras-chave: Gutiérrez Girardot, José Luís Romero, historiografia, identidade, utopia, Latino-America,filosofia.

\section{Presentación}

En Cien años de soledad Gabriel García Márquez habló de la “peste del insomnio” que azotó a Macondo. La consecuencia del insomnio colectivo fue el "olvido”, gracias al cual la gente se hundía en "una especie de idiotez sin pasado” (García Márquez, 2007, 
p. 49 y ss.). Son estas “evasiones de la memoria” lo que Rafael Gutiérrez Girardot llamó la "peste del olvido", con lo cual significaba que en Hispanoamérica gracias a esa "idiotez sin pasado", esto es, a la falta de tradición, se dejaron y olvidaron autores que fueron arquitectos de América, entre ellos, Alfonso Reyes, Pedro Henríquez Ureña y, a quien van dedicadas estas líneas, José Luis Romero.

Romero fue víctima en Hispanoamérica de esa "peste del olvido". Un historiador ejemplar, conocedor como ninguno de la historia occidental, desde Grecia, pasando por Roma, la Edad Media, la Edad Moderna, hasta internarse en su Argentina y en América Latina. Sus obras así los testimonian, entre ellas: La crisis de la república romana (1942), Maquiavelo historiador (1943), La Edad Media (1945), La revolución burguesa en el mundo feudal (1967), Crisis y orden en el mundo feudoburgués (1980), El ciclo de la revolución contemporánea (1948), Las ideas políticas en Argentina (1946), Latinoamericana: situaciones e ideologías (1967), Latinoamérica: las ciudades las ideas (1976). Con muchos de estos libros Romero hizo, según Gutiérrez, importantes contribuciones a la historiografía europea, pues tales estudios sobre Europa superan trabajos realizados en el viejo mundo sobre los mismos temas. Los trabajos sobre América Latina aún no tienen equivalente.

Una de las labores del colombiano Rafael Gutiérrez Girardot fue, precisamente, rescatar esos autores olvidados que habían fundado la tradición latinoamericana. Autores que eran ejemplo de rigurosidad, sistematicidad investigativa, cosmopolitismo y compromiso con Hispanoamérica. De ahí la alta valoración que tenía el crítico por la obra del historiador argentino. Obra de la que fue un gran conocedor y de cuyo conocimiento dejó prueba en ensayos como Pedro Henríquez Ureña, Alfonso Reyes, José Luis Romero. El intelectual y el científico, Sobre el problema de la definición de América. Notas sobre la obra de José Luis romero, La significación continental de José Luis Romero, así como el libro titulado Historia, sociedad, cultura y praxis política en José Luis Romero, del cual fue editor, publicado en España en 1995.

Un escrito fundamental que da testimonio del afecto de Gutiérrez por Romero es el prólogo que el crítico literario hizo del libro Latinoamérica: las ciudades y las ideas, en la edición de la Universidad de Antioquia, 1999. En ese prólogo se encuentra implícita la explicación de por qué Romero era para el filósofo colombiano una "afinidad electiva”. En él hallamos los motivos por los cuales el hispanista y germanista consideraba al historiador argentino un “Arquitecto de América”. Es a partir de ese 
prólogo y de algunos otros ensayos, que estableceré en adelante la relación entre los dos autores "maestros de América" y mostraré sus puntos de convergencia.

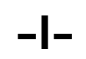

En el Prólogo a Latinoamérica: las ciudades y las ideas, en las líneas finales, sostiene el autor de Modernismo:

La obra de José Luis Romero no es solo un programa de renovación de la historiografía latinoamericana, ni solo un supremo ejemplo de la relación creadora con la cultura europea. Es modelo de una historia total, fundamental en el sentido del vasto campo que abarca y del esclarecimiento de la "vida histórica" que da sentido concreto a lo que vagamente se ha llamado conciencia de América, e invita a perfilarla y a contribuir a su dinámica... (Gutiérrez Girardot, 1999, p. 18).

Son precisamente dos aspectos señalados en esta cita que me interesan: "la historiografía de José Luis Romero", en primer lugar; y su relación con la "conciencia de América", en segundo. En efecto, la relación de las obras del colombiano y el argentino gira alrededor de estos dos ejes: historiografía y "definición de América”; definición y conciencia de nuestra cultura que implica una utopía política. Ocupémonos, ahora, del primer aspecto.

La historiografía de José Luis Romero, sin duda, significó una renovación para la historiografía latinoamericana. Con ella, el ex-rector de la universidad de Buenos Aires superó una historia ideológica puesta al servicio de la construcción de la nacionalidad como lo fue la historia en el siglo XIX y gran parte del siglo XX. Esa historia nacionalista variaba de acuerdo a los partidos. Asimismo, sus presupuestos metodológicos eran realmente pobres. Pues solo se fijaban en hechos y desechaban los contextos históricos. Era una historia anecdótica, basada en fechas, acontecimientos aislados, que relataba las hazañas de los héroes de la independencia. Esa historia, como se dijo, estuvo ineludiblemente sometida a los pobres de turno y a la visión que estos quisieran dar del pasado.

En Colombia, la pobreza de la historia se manifestó y, desgraciadamente, aún se sigue manifestando en algunos historiadores vivos, entre ellos, varios liberales. La pobreza 
de nuestra historia solo empezó a variar un poco con los estudios de hombres como Camacho Roldán y Miguel Samper en el siglo XLX. Ellos se preocuparon por los fenómenos sociales, las clases, los problemas económicos, dilucidaron las causas por las que la economía colonial impidió el oportuno desarrollo de la República. Esto es algo que se puede comprobar si se estudia el fundamental libro La miseria en Bogotá (1967) de Miguel Samper. Camacho Roldán y Miguel Samper fueron, como bien lo anotó otro de los renovadores de la historiografía colombiana, Luis Eduardo Nieto Arteta, precursores de la "sociología americana", lo cual incluyó la dilucidación de problemas históricos, entre ellos, la relación de la anarquía económica con la política para explicar el fenómeno de las guerras civiles que azotaron el largo siglo XIX (Nieto Arteta, 1978, p. 145).

Habría que mencionar aquí al profesor Luis López Mesa, quien con estudios como Disertación sociológica (1939), Escrutinio sociológico de la historia de Colombia (1955) y De cómo se ha formado la nación colombiana de 1934, aportó a los estudios históricos y sociológicos del país. El mérito de López de Mesa consiste en que realizó intentos de encontrar las causas de los hechos históricos y sus conexiones. Es decir, acudía al casualismo positivista, descriptivo, como lo hicieron también Camacho y Samper. Con todo, en su libro citado en 1934, cuando se adentra en el estudio de nuestra historia constitucional, inserta unas curiosas gráficas donde los gobiernos liberales aparecen en ascenso y los conservadores y sus respectivas constituciones en descenso. Ascenso y descenso de la libertad, respectivamente (López de Mesa, 1970, p. 161). Es decir, aquí se ve claramente que no hay un intento de aplicar la "neutralidad valorativa", de desligar la historiografía de la ideología y la política.

En Colombia estas deficiencias en la historiografía y su metodología solo dan un giro abrupto con el ya mencionado Nieto Arteta. Ese giro puede verse en dos momentos: en su juventud cuando utiliza el marxismo para sus estudios de la realidad colombiana y en los años 40 en su libro Economía y cultura en la historia de Colombia (1941). En este texto decía Nieto en clara oposición a la historiografía anterior: "nuestros historiadores oficiales son impertérritos: no se arredran ante ninguna falsificación siempre que ella cree un artificioso apoyo a la concepción inexacta que se quiere fecundar y demostrar. Torturan inmisericordemente a los hechos históricos. Aplican a la historia una camisa de fuerza, elaborada dentro de las medidas indicadas por el sistema cuya autenticidad se quiere verificar a todo trance. El sistema y no el hecho, es lo valioso (Nieto Arteta, 1996, p. 229). 
El panorama mejoró en nuestro país con la obra de Jaime Jaramillo Uribe, en especial su libro Ensayos sobre historia social colombiana (1968). Lo mismo no puede decirse de su fundamental El pensamiento colombiano del siglo XIX, que resulta siendo limitado, pues se centra en la exposición de las ideas de los autores estudiados en desmedro del contexto histórico-social. Esa mejora se hizo más notoria con la normalización en la recepción del marxismo en nuestro país. Fruto de esa recepción fue el libro Estudios sobre el subdesarrollo colombiano (1963) de Mario Arrubla. De ahí en adelante, puede decirse, se dio en la historiografía colombiana lo mismo que ya se estaba dando en el campo de la filosofía, esto es, la "normalización".

He mencionado los hechos anteriores porque son indicativos de la situación de nuestra historiografía. Y para mencionar, de paso, que la obra de José Luis Romero, desde bien temprano, había superado muchos de esos escollos. Basta mirar sus textos de los años cuarenta para comprobarlo. Romero se preocupó siempre por los procesos, sus variaciones y disparidades. Concebía la historia en continuo movimiento. Hablaba por ello de equilibrios inestables, de crisis y revoluciones. Atendía preferentemente a las novedades y a la forma como estas podían virar el movimiento de la realidad sociocultural. Su reto fue una historia total, por eso se definió como un historiador de la cultura, entendida esta en el sentido más amplio. Su historia fue una "historia de las ideas", de las mentalidades de los diversos grupos sociales, de las tensiones entre estos; de la recepción de las ideas por los diversos sectores y su relación con el contexto social; se fijó con "rigor histórico" en los condicionamientos recíprocos entre realidad e ideas. Son todos estos aspectos los que lo ponen al nivel de la moderna y renovadora historiografía francesa de los Annales, escuela fundada en 1929 por Lucien Fevre y Marc Bloch; perspectiva historiográfica a la que se sumaron posteriormente Fernando Braudel y Jacques Le Goff. La obra de Romero nada tiene que envidiarle, pues, a esa corriente historiográfica. Él fue un receptor crítico de los Annales, pero su obra, como lo han indicado varios conocedores, es auténtica. De hecho su historiografía recibió el reconocimiento de Braudel y del mismo Le Goff, tal como puede apreciarse en el prólogo a una reciente edición de Crisis y orden en el mundo feudoburgués (2003), libro que quedó inconcluso a la muerte de Romero y que hace parte de los cuatro tomos que previó sobre la evolución de la burguesía, desde el siglo III d. C., hasta el siglo XX.

En su ensayo Los puntos de vista: historia política e historia social de 1965, el escritor argentino llamaba a "superar" la historia política predominante en 
América Latina ${ }^{1}$. Esa historiografía había sido el canon del siglo XIX y parte del siglo XX. Romero mostró en el ensayo citado las nuevas posibilidades que la historia social abrió en los estudios sobre la independencia: "el problema de las influencias ideológicas se combinó con el de los grupos que promovieron o se opusieron al cambio, y el análisis económico social de esos grupos renovó de raíz el tema de la emancipación [...]. Se vio en ellos [los grupos] sectores de la burguesía urbana con intereses definidos y opuestos a los de otros grupos, se identificaron más precisamente los caracteres de su mentalidad y de sus actitudes, y en ellas se percibieron los puntos donde podían arraigar las influencias ideológicas extranjeras y favorables al cambio (Romero, 2001, p. 11-12).

Es este conjunto de aspectos sobre la independencia los que el historiador argentino muestra magistralmente en su famoso ensayo El pensamiento político de la emancipación de 1977 y que aparecen también en su magistral Latinoamérica: las ciudades $y$ las ideas.

Sin duda, es Latinoamérica: las ciudades y las ideas el libro cumbre de Romero. Es un libro fruto de una larga investigación, que está relacionado directamente con los estudios clásicos del historiador argentino, entre ellos, La revolución burguesa en el mundo feudal y Crisis y orden en el mundo feudoburgués. La ocupación con la ciudad caracterizó gran parte de la obra de Romero. Aun en el libro tan breve como La Edad Media (1949), aparece esta impronta (Romero, 2002, p. 62 y ss.). El argentino se interesó siempre por el papel que la ciudad jugó en el nacimiento, desarrollo y consolidación del mundo burgués. Es decir, él encontró que la ciudad era un elemento indispensable para el estudio de la mentalidad burguesa, que existía una inescindible relación entre burguesía y desarrollo urbano. De tal manera que Latinoamérica continúa con el estudio de la ciudad pero en América Latina. Antecedentes directos de este libro son los ensayos: La ciudad Latinoamericana: continuidad europea y desarrollo autónomo (1969) y La ciudad latinoamericana y los movimientos políticos (1969).

El libro de Romero de 1976 no es una historia de las ciudades en América latina. Es, como el propio autor sostuvo, el estudio del "papel que las ciudades han cumplido en el proceso histórico latinoamericano". Aquí es necesario decir que Romero siempre

1 Debe entenderse aqui que Romero no llamaba a desechar la historia política. Él mismo la incorporó a sus trabajos pero teniendo siempre presente la fuerza que las ideas políticas tenian en una determinada época o momento histórico. 
defendió la peculiaridad de los procesos hispanoamericanos. Así lo hizo al analizar la independencia cuando dijo: "El proceso de Emancipación se desata en tierra americana a partir de situaciones locales, y desencadena una dinámica propia que no se puede reducir a la que es propia de los procesos europeos contemporáneos" (Romero, 2001, 51-52). En este mismo sentido, el desarrollo de la ciudad en América no fue una simple repetición del proceso en Europa. Aquí adquirió una dinámica propia. Por eso habló de "desarrollo autónomo y heterónomo".

Refiriéndose a los cambios producidos en los siglos XVIII y XIX sostiene el historiador argentino:

En rigor, todas las ciudades latinoamericanas aceleraron a partir de entonces [siglo XVIII] un doble proceso que estaba iniciado desde la fundación. Por una parte procuraban adecuarse al modelo europeo siguiendo sus líneas de cambio y por otra sufrían las transformaciones derivadas de su estructura interna, que alteraban las funciones de la ciudad, $y$, además, las relaciones entre los distintos grupos sociales y entre la ciudad y la región [...]. Los sectores postergados durante la época colonial [...], hicieron irrupción en la vida pública, pidiendo su parte en el poder y buscando ascenso social, con los cual se incorporaron a las sociedades urbanas nuevos grupos que le imprimieron un aire vernáculo. Así se intensificó el proceso de desarrollo autónomo. Pero entre tanto un nuevo impacto externo -el de la sociedad industrial- se hizo sentir sobre las ciudades activas en las últimas décadas del siglo XIX y forzó su desarrollo heterónomo, hasta incluirlas plenamente en el sistema económico del mundo capitalista (Romero, 1999, p. 33).

En esta cita encontramos aspectos y elementos claves que trata Romero en su libro. Los grupos, sus mentalidades, las transformaciones de la ciudad, su impacto y su tensión recíproca con el campo, la recepción de las ideas europeas y la peculiar adaptación que tuvieron en América, etc., hay que poner de presente aquí que un aspecto a resaltar de este libro es la permanente atención de Romero a las mentalidades. En el texto se habla de las mentalidades conquistadora, hidalga, hidalgoburguesa, criolla, patricia, burguesa. Hay que decir, además, que solo un seguimiento cuidadoso de los procesos que magistralmente describe Romero permite entender por qué se puede hablar de oligarquías liberal burguesas, de pensamiento liberal-conservador o de mentalidad hidalgoburguesa. 
Ahora, toda esta concepción de la historia, la metodología de Romero, sus temas de estudio, etc., no representa un mero prurito de erudición. Romero siempre rechazó lo que podemos llamar la "historia por la historia". Es conocida su frase: "La historia no se ocupa del pasado. Le pregunta al pasado cosas que le interesan al hombre vivo". Esto denota en el argentino un interés por la realidad en que vive, en que se encuentra. Romero no fue un intelectual en la "torre de marfil". Además de su brillante carrera como historiador, ocupó cargos administrativos en la Universidad de Buenos Aires y militó políticamente. Era consciente de que la historia no consistía en una cantidad de información vacía y en un conjunto de datos sobre el pasado. Él veía en las enseñanzas de la historia -pues según decía, la historia era maestra- la posibilidad de comprender el presente, de dilucidar la manera como hemos llegado a ser lo que somos para, partiendo de ahí, vislumbrar el futuro, la utopía de América, la América como "patria de la justicia", como decía su maestro Pedro Henríquez Ureña.

Romero buscó en el mundo feudal y en la Edad Moderna el surgimiento de la mentalidad burguesa, su constitución, consolidación, apogeo y crisis. Con los cual rastreaba nuestros orígenes en una de nuestras "inevitables tradiciones". Sus investigaciones históricas esclarecieron cómo procesos europeos e instituciones "determinaron la constitución cultural del nuevo mundo" (Gutiérrez Girardot, 2004, p. 272). Aquí es válido mencionar que Omar Achá, de la Universidad de Buenos Aires, ve en Latinoamérica no solo un trabajo histórico, sino una posición política. El libro, según Achá, busca mostrar la necesidad de tomar postura frente al destino nacional. Se hace necesario entonces superar la escisión social, la sociedad vertical-jerárquica, que Romero muestra en cada momento histórico de nuestra convulsionada historia. Romero buscaba superar esa anomia de las sociedades, confiando en una élite que dirigiera el proceso y corrigiera esa escisión. Es decir, él buscaba ilustración y progreso porque consideró, en últimas, que América debería lograr los niveles culturales y sociales de Europa. El profesor de la Universidad de Buenos Aires llega a decir que las élites son el tema de Latinoamérica (Achá, Ideas ciudades y élites). Acertada o no esta lectura, lo cierto es que él le dio una función esclarecedora y emancipatoria a la historia. Todo esto explica la importancia que le daba a la pedagogía educativa y a la enseñanza de esta disciplina. La historia incitaba a pensar al estudiante sobre el mundo que lo rodeaba, sobre sus circunstancias. Así lo aseguró en varias entrevistas. 


\section{-II-}

En esta parte mostraremos que lo que el colombiano Rafael Gutiérrez Girardot llamó "una historia social de la literatura hispanoamericana", tiene ecos y enlaza con una historiografía de Romero y con la concepción que él tiene de ella. A la vez pondremos de presente que la historia para Gutiérrez, ya sea la de Romero (también lo fueron los aportes de Alfonso Reyes y Henríquez Ureña) o su "historia social de la literatura", tiene una función primordial en el proyecto de una "definición de América”, esto es, que la historia es fundamental para esclarecer qué somos, para tomar "conciencia de América", en reemplazo de las "especulaciones turbias" sobre el 'ser', la 'identidad latinoamericana', la 'originalidad', etc., que enarbolaron muchos filósofos latinoamericanos en la misma época de José Luis Romero, entre ellos, Leopoldo Zea y Augusto Salazar Bondy.

Rafael Gutiérrez Girardot, filósofo, sociólogo, crítico literario, fallecido en Alemania en mayo de 2005, fue uno de los intelectuales más grandes que ha producido el continente. Gutiérrez, como Romero, fue un maestro de América. Eso se comprueba con solo acudir a su vasta obra: más de 20 libros. Entre ellos: Modernismo, Supuestos históricos y culturales, Horas de estudio, El fin de la filosofía y otros ensayos, Aproximaciones, Provocaciones, Cuestiones, Heterodoxias, Nietzsche y la filosofía clásica, La imagen de América en Alfonso Reyes, Borges: el gusto de ser modesto, tradición y ruptura, etc. Fue, a pesar de las múltiples críticas que pueden hacérsele (Pachón Soto, 2006, p. 115-132), un intelectual riguroso, sistemático y polémico. Tuvo una innegable vocación pedagógica con la cual llamaba a los latinoamericanos a abandonar la simulación cultural. Dentro de su legado podemos nombrar los siguientes: la crítica de la mediocridad, la superficialidad, el esquematismo, la simulación y la improvisación de muchos intelectuales colombianos, latinoamericanos y españoles, entre ellos, para solo mencionar tres: Ortega y Gasset, Octavio Paz y Camilo José Cela; la crítica de la universidad privada por concebir la educación como un negocio y a sus estudiantes como clientes; el llamado a rescatar de la "peste del olvido" a los intelectuales latinoamericanos constructores de América, esto es, a rescatar la tradición; la difusión en Europa de la cultura y las letras latinoamericanas, por ejemplo, la de Borges; la difusión e introducción en España, América Latina y, por supuesto, Colombia, de gran parte del pensamiento alemán, entre ellos, el de Walter Benjamin; el llamado a asumir críticamente la tradición y el pensamiento europeo; la lucha constante contra las modas académicas; el imperativo de adquirir una formación en idiomas y en cultura universal, que hiciera de la 
intelectualidad latinoamericana un sector cosmopolita, que permitiera dialogar de tú a tú con Europa y Norteamérica; la instauración entre nosotros de formas rigurosas y sistemáticas de trabajo y la necesidad de instaurar la crítica en "las Españas". Por último, su propuesta, a mi juicio, la más importante y original de una "historia social de literatura". Nos detendremos en este último aporte.

La propuesta de una historia social de la literatura la encontró Gutiérrez en la obra Las corrientes literarias en la América hispánica (1945, traducida al español en 1949) del dominicano Pedro Henríquez Ureña. Así lo expresa en la “advertencia” de su libro Aproximaciones de 1986, cuando dice:

\begin{abstract}
Escritos para diversos públicos y ocasiones, ellos [los ensayos que contiene el libro] parten de la historiografía literaria de Pedro Henríquez Ureña, a la que pretende profundizar, ampliando el camino o los caminos que ella abrió y que se han echado al olvido (Gutiérrez Girardot, 1986, p. 7).
\end{abstract}

Esto explica por qué en el mismo libro aparece el ensayo La historiografía literaria de Pedro Henríquez Ureña, escrito en el cual el colombiano señala ese camino abierto por el dominicano. Es decir, allí muestra las perspectivas que abrió el autor de Las corrientes para una historia social de la literatura. Entre estas perspectivas, que deben ser "profundizadas", menciona el crítico colombiano: la periodización de la literatura en Hispanoamérica, proceso que ubica con la creación y formación de la "nueva sociedad" y no con la literatura precolombina; la relación dialéctica entre fenómeno social y literatura y vida literaria; el vislumbre de una sociología del intelectual y del saber; la formación del hombre de letras y su profesionalización; el estudio del costumbrismo mirado socio-históricamente; así como estudios sobre la familia y la religión, etc., (p. 65-86).

El tema de la "historia social de la literatura" es asumido por Gutiérrez en ese mismo libro. Su ensayo Problemas y temas de una historia social de la literatura latinoamericana es ya una "profundización” de las inquietudes abiertas por Henríquez Ureña. Por tal razón menciona que existen problemas teóricos, como la transposición de la metodología de una historia social, "ciencia conclusa y principal”, a una ciencia inicial y derivativa como la "historia social de la literatura". El colombiano dirá finalmente que una historia social de la literatura no aplica métodos elaborados $a$ priori al material literario, sino que sus presupuestos se van construyendo en la praxis 
misma, eso sí, partiendo de lo que ya se tiene. Para ellos es necesario trabajar con el concepto de "totalidad histórica", a saber, una historia total de la sociedad tal como la concibió Pierre Villar. De ahí se derivan los temas que deben estudiarse en el intento de construir una historia tal: el estudio de la sociedad colonial, de la encomienda; de la hacienda, no ya desde la perspectiva jurídica, sino como institución social que refleja una visión del mundo que subyace a la nueva sociedad jerárquica, es decir, la sociedad donde nació esa literatura; el estudio de la historia misma de España, la investigación sobre el proceso de secularización en América y la recepción que tuvo en estos países el Código Civil de Andrés Bello y su relación con la mencionada secularización y racionalización de la sociedad; la formación del intelectual, el cambio de función de la literatura, la bohemia; el estudio de la producción, difusión y consumo de la literatura, esto es, la investigación sobre los editores, existencia de revistas, periódicos, salones de lectura, público lector, etc., (p. 47-64).

Estos temas fueron tratados de nuevo por Gutiérrez Girardot en la Universidad Nacional en el año de 1987, época en la cual también dictó un seminario sobre la famosa (rica y compleja) introducción de la Fenomenología del espíritu de Hegel. En esa ocasión puso de presente las limitaciones para emprender la elaboración de una historia social de la literatura: mencionó problemas teóricos y prácticos. Dentro de estos últimos la inexistencia de archivos sobre la correspondencia de los escritores, la falta de autobiografías; asimismo volvió sobre el tema de la precariedad de los estudios sobre la sociedad colonial, por ejemplo, sobre la religión. Hizo énfasis en el estudio de la formación del hombre de letras hispanoamericano, su contacto con otros escritores, su concepción del oficio de escritor y de la relación de este con la sociedad. En términos generales, volvió a insistir, aunque de manera más profunda y detallada, en aspectos que había mencionado en su ensayo del año anterior. De ahí salió un pequeño libro titulado Temas y problemas de una historia social de la literatura hispanoamericana, que se publicó en 1989, es decir, tres años después del esbozo en Aproximaciones. Además, como puede verse, el libro varía un poco el título del ensayo mencionado.

Lo interesante de lo anterior para este escrito es que ese programa que enarboló Gutiérrez tenía una clara vocación política. En la "advertencia" de Aproximaciones había dicho:

Esta historiografía está animada por un propósito bolivariano y martiano que tiene, consecuentemente, proyecciones políticas, esto es, la de la unidad 
de nuestra América como única posibilidad de una emancipación real y de la realización política de nuestra América como patria de la justicia [...], esta historiografía y la concepción política que subyace a ella, excluye de por sí los nacionalismos y las diversas variaciones de este, como el indigenismo, cuyo fantasma se mantiene a pesar de su fracaso literario (1986).

Y en el texto mencionado de 1989, que se incluyó completamente en el libro El intelectual y la historia, publicado en Venezuela en el año 2001, reiteró ese compromiso político de su proyecto, así como la relación que tal programa historiográfico tenía con la llamada "conciencia de América". Sostuvo:

La elaboración de una historia social de la literatura latinoamericana en general y de la colombiana en particular, es una exigencia que puede satisfacer múltiples necesidades y evitar especulaciones aventuradas y aventureras como las del pseudoproblema de la identidad cultural. Pues una historia social de la literatura contribuiría a dar respuestas a problemas de los que, por naturaleza, no se ocupan la historia económica y la historia social que se practica actualmente, como el del largo y difícil tránsito de la sociedad tradicional a la sociedad moderna, y que se encuentra en autobiografías, correspondencias y en una literatura nostálgica del pasado (Gutiérrez Girardot, 2001, p. 112).

El punto de partida, como se dijo, tiene que ser la tradición. De tal forma se la asimila y enriquece con nuevas lecturas, lo que a la vez permite una recepción crítica y dialógica del pensamiento extranjero. Este punto es interesante, porque Gutiérrez fue consciente de que la importación acrítica de las modas intelectuales entre nosotros era producto de nuestra falta de tradición y su desconocimiento. La historia social de la literatura que propuso abogaba por la superación de esa limitación.

La historia social de la literatura, pues, tiene en Gutiérrez una función política, utopista:

La de hacer consciente a la sociedad de lo que ella es y cómo ha llegado a ser lo que es, y la de señalar, a través de la crítica, metas utópicas, es decir, contribuir a dinamizarla $[\ldots]$ la de rescatar, actualizar y vivificar la tradición menospreciada [...]; y la de recuperar por este camino la conciencia de la unidad de Nuestra América, que es el único freno a la creciente atomización de nuestras sociedades. 
Estas sociedades vejadas por quienes deberían defenderlas y dirigirlas, tienen hoy un único soporte y esperanza de recuperar su fuerza unitaria, y este es el intelectual (2001, p. 147).

Aquí el intelectual, al igual que en la utopía de Alfonso Reyes, juega también un papel primordial.

Hay que decir, que este proyecto del filósofo y crítico colombiano no se quedó en la mera teoría. El mismo Gutiérrez realizó estudios que materializaron parte de los supuestos de su programa. Basta leer ensayos como La formación del intelectual hispanoamericano en el siglo XIX, publicado en 1992 o el sugestivo trabajo Estratificación social, cultura y violencia en Colombia (2000), donde acudiendo a una historia social de la literatura, en especial con las obras de José María Vergara y Vergara y José María Samper, así como con fuentes de la historiografía tradicional, esclarece precisamente "cómo es" la sociedad colombiana y "cómo ha llegado a ser lo que es". Es decir, explicita eso que Antonio García llamó el "Estado de casta” o la "Republica señorial” y que en palabras del polemista y crítico colombiano toma el nombre de "Republica monárquica” (Gutiérrez Girardot, 2005).

Una vez aquí, veamos cómo se relaciona todo esto con José Luis Romero. Habría que decir que ambos tienen una concepción igual de América Latina. Es decir, América es hija de la "era del capital" y del proceso de "unificación del mundo" (Hobsbawn). Para Gutiérrez, eso fue lo que demostró Romero con sus trabajos historiográficos. El Nuevo Mundo es fruto de un proceso de “europeización”, el cual es claro, por ejemplo, en Latinoamérica: las ciudades y las ideas. Sin que esto quiera decir, que aquí no se hayan constituido procesos propios. Al respecto dijo Gutiérrez: "la sociedad latinoamericana es no solamente el producto de la sociedad europea trasplantada e impuesta en el Nuevo Mundo, sino de la paulatina asimilación de lo europeo en Latinoamérica" (Gutiérrez Girardot, 1989, p. 48), en eso consiste su especificidad histórica. También agrega: "La sustancia institucional y cultural de Latinoamérica es europea" (p. 52).

Es en esta definición de Hispanoamérica donde entra la historiografía de Romero a jugar un papel importante. El punto de partida lo podemos mostrar en un juicio de Gutiérrez sobre la obra de Romero:

José Luis Romero destruye la imagen folclórica y exótica europea de Hispanoamérica, pero imposibilita las especulaciones de muchos 
hispanoamericanos sobre el 'ser' de América, sobre el determinante indígena de la cultura y la sociedad, sobre 'indoamérica' o 'Amerindia', que subyacen a una ideología irracionalista, 'telurista', con complejo anti-modernos y soluciones totalitarias como todos los populismos (Gutiérrez Girardot, 2004, p. 272).

Pasemos a explicar esto.

El ensayo de Gutiérrez Girardot titulado: Sobre el problema de la definición de América. Notas sobre la obra de José Luis Romero, comienza mostrando cómo en la época en que aparece la obra del argentino, en América Latina se vive un momento de "especulaciones pseudo filosóficas sobre el 'ser' de América". Entre los especuladores se menciona a José Gaos "y sus discípulos", entre ellos, como es bien sabido, se encuentra el filósofo mejicano Leopoldo Zea, también se menciona a Edmundo O'Gorman y, como se puede constatar en otros ensayos del colombiano, Salazar Bondy cae en ese grupo.

El colombiano sostiene que el trabajo de Edmundo O 'Gorman sobre el descubrimiento buscaba desmitificar la historiografía sobre ese importante acontecimiento con el fin de "despejar el campo en el que se divisen la idea y el ser de América" (Gutiérrez Girardot, 1998, p. 257). Sin embargo, lo que precisamente enseñó José Luis Romero fue que la pregunta por "lo americano", "el ser de América" era un pseudo-problema, porque quienes lo asumieron así estaban buscando una "idea”, estaban tras un "platonismo" y no comprendieron que la filosofía no era competente para enfrentarse al problema del 'ser' de un ente histórico como el de América. El problema de América y de su especificidad es un problema historiográfico. Sostiene Gutiérrez:

La filosofía se ocupa del 'ser' ciertamente, pero el 'ser' de una entidad histórica ya no es objeto de la filosofía, a menos que se ignore la significación del genitivo y en vez del 'ser' con que se ocupa la historia, esto es, las condiciones materiales de la vida, se coloque una idea platónica. Los trabajos que se elaboraron bajo el signo de este platonismo sumario e inconsciente y que han encontrado sus continuadores hasta hoy, buscaban determinar la originalidad de la filosofía americana, lo cual suponía el conocimiento previo de lo americano. Pero como 'lo americano' no es deducible especulativamente, las categorías elaboradas para describirlo se movieron en el campo de la vaguedad y abrieron las puertas a la confusión entre lo que es y lo que debe ser (p. 258). 
El colombiano sostiene, además, que en este mismo sentido se movía la pregunta por la identidad de América, con lo que se trasladaba un concepto de la psicología social, esto es, el de la identidad personal al de un ente histórico (Gutiérrez Girardot, 1997). Todos estos problemas no eran más que un "recorrido diletante" (sic).

La obra de José Luis Romero ignoró esa problemática o, más bien, esa "embriaguez". Porque su perspectiva historiográfica americana no se sumergió en esos problemas, que más bien testimoniaban la incapacidad científica de los hispanoamericanos, sino que él demostró que no solo Europa estaba legitimada para hacer historia, más precisamente, historiografía. Por eso su escrito sobre la crisis de la republica romana es el primer aporte de lengua española a la historiografía sobre Roma. Romero comprendió que:

La reflexión de quien se ocupa con entidades históricas en nada se asemeja a la reflexión filosófica [...]. Su reflexión se concentró en un detallado examen de 'las cosas mismas', y estas son, en el caso de las entidades históricas, los acontecimientos concretos, los movimientos sociales y políticos, las ideologías, las estructuras sociales y económicas" (Gutiérrez Girardot, 1998, p. 263).

Aquí se entiende perfectamente por qué Romero no sucumbió a la moda de la problemática por el 'ser' de América, la pregunta por 'lo propio': porque esas preguntas buscaban una definición esencial, a priori, y no la comprobación histórica, ni la descripción de los procesos, del devenir de la formación histórica de América. Romero mostraba dos polos en su reflexión: la historia europea y la historia latinoamericana y se concentraba en el proceso de la formación de "las configuraciones sociales". Esta perspectiva era la correcta.

Según el crítico boyacense, la perspectiva historiográfica de Romero también evitaba las especulaciones sobre la "originalidad". Como en el caso de Henríquez Ureña y Reyes, el problema ni está referido a algo específicamente latinoamericano, que presupondría la discusión sobre el 'ser' de América, sino al rigor científico, a la forma como se produce algo: "la calificación científica no depende de la 'originalidad' sino del conocimiento fundado de las fuentes, del rigor con que se las maneja, de la limpieza y precisión en la formación de los conceptos”.

La pregunta por el ser de América, el problema de la originalidad de la filosofía, el de la identidad, etc., son ecos del irracionalismo de los años treinta de Europa, entre otros, de las perspectivas de raza, el intuicionismo, las filosofías de la vida, etc., que 
precisamente ponen los acentos en aspectos telúricos, en esencias, en "lo propio" y no en procesos sociales, económicos y culturales. Las perspectivas indigenistas (indoamérica) son reflejo también de esos irracionalismos. José Luis Romero, pues, supera todos esos malos presupuestos filosóficos:

Pues él tradujo a nuestra lengua la historia de Europa y con eso enseñó a conocerla, a tomar conciencia de una de nuestras inevitables tradiciones. Ese conocimiento es lógicamente el presupuesto del conocimiento de lo que somos, pero no en el sentido del ser abstracto y especulativo" (Ibíd., p. 265).

La "originalidad" de un proceso histórico solo es definible cuando se lo confronta con el horizonte total dentro del cual se realiza, frente al cual se pretende poseer una determinada especificidad. Solo cuando se conoce la historia y la cultura europeas, pues, es posible definir en qué consiste la 'originalidad' de Latinoamérica (Ibíd., p. 266).

Podemos comprender por qué Gutiérrez Girardot escoge a Reyes, Henríquez Ureña y Romero para afrontar el problema de la "definición" de Hispanoamérica: "los tres modelos de intelectual y científico llevan, de por sí, un desafío a la actual inteligencia hispanoamericana: saber detallado, conceptualización clara, honradez intelectual, exposición comprensible a todos, invitación a 'merecer nuestras patrias, a ganarlas, a conquistarlas' apasionadamente". Esto es, entre otras cosas, cosmopolitismo y rigor intelectual.

Hay que decir aquí que Gutiérrez desconoce u omite un aspecto interesante, pero en últimas anecdótico, del joven José Luis Romero. En efecto, en la Revista Sur No. 8 de 1933, el argentino publicó una reseña sobre el libro Meditaciones sudamericanas del conde Hermann Alexander Keyserlin, "Un verdadero hijo de puta" al decir de Fernando González (González Ochoa, 1973, p. 30), donde el joven historiador precisamente asumía la visión telurista de un "suramericanismo esencial”. Recordemos por ejemplo, que el afamado conde báltico afirmaba que Suramérica era el “continente de la tristeza". El profesor Gerardo Oviedo, de la Universidad de Buenos Aires, en su artículo La idea del americanismo en el joven José Luis Romero, ha mostrado las posibles causas por las que el joven Romero aceptó esa visión de América, la cual es claramente rechazada en sus escritos posteriores.

Para concluir, podemos plantear los siguientes puntos de convergencia entre Romero y Gutiérrez Girardot: ambos fueron autores bien formados, con un "conocimiento 
detallado" y amplio de la historia latinoamericana y europea. En este sentido ambos fueron intelectuales cosmopolitas. Los dos concibieron a Hispanoamérica de la misma forma, esto es, como producto de Europa; tanto como el colombiano como el argentino le dieron una función política y pedagógica a la historia. Esta servía para rescatar la tradición y para responder preguntas del hombre actual y así obtener respuestas para construir el futuro. Estas, a su vez, servían de base para realizar la utopía de América. Hay que decir, además, que ambos bebieron de la literatura y que en este aspecto, Henríquez Ureña influyó en ambos. Habría que suponer también que Romero le brindó a Gutiérrez muchas perspectivas con su libro Latinoamérica: las ciudades y las ideas, pues en él la literatura camina de la mano con la historiografía para mostrar cómo esta sirve para esclarecer y dilucidar aspectos de la vida cotidiana y social de los pueblos de este continente. Además, es válido pensar que la preocupación de Romero por las ciudades influyó en el libro Modernismo. Supuestos históricos y culturales de 1983, pues allí Gutiérrez muestra cómo este movimiento literario es hijo de la era del capital, del proceso de secularización, del crecimiento urbano y de las perspectivas influencias que estos fenómenos tuvieron sobre los escritores y la vida literaria. Sin duda, en esa empresa, Romero alumbró parte del camino del filósofo colombiano.

\section{Referencias}

Achá, O. (s.f.). Ideas, ciudades y élites. Recuperado el 8 de noviembre de 2007, de foroiberoideas.cervantesvirtual.com/reseñas/dara/23.pdf

García, G. (2007). Cien años de soledad (edición conmemorativa). Real Academia Española, Asociación de Academias de la Lengua Española, Alfaguara.

González, F. (1973). Los negroides. Medellín: Bedout.

Gutiérrez, R. (1986). Aproximaciones. Bogotá: Procultura.

(1989). Hispanoamérica: imágenes y perspectivas. Bogotá: Temis.

. (1997). La identidad hispanoamericana. En Provocaciones, 201-209. Bogotá: Ariel.

(1998). Sobre el problema de la definición de América. Notas sobre la obra de José Luis Romero. En Insistencias. Bogotá: Ariel. 
(1999). Prólogo. En J. L. Romero, Latinoamérica: las ciudades y las ideas. Medellín: Universidad de Antioquia.

. (2001). Temas y problemas de una historia social de la literatura hispanoamericana. En El Intelectual y la historia. Caracas: La Nave Va.

. (2004). Pedro Henríquez Ureña, Alfonso Reyes, José Luis Romero. El intelectual y el científico. En Heterodoxias. Bogotá: Taurus.

. (2005). Estratificación social, Cultura y violencia en Colombia. Aquelarre, $4(8), 85-98$.

López de Mesa, L. (1970). De cómo se ha formado la nación colombiana. Medellín: Bedout.

Nieto, L. E. (1978). Ensayos históricos y sociológicos. Bogotá: Instituto Colombiano de Cultura. . (1996). Economía y cultura en la historia de Colombia. Bogotá: El ÁncoraBanco de la República.

Pachón, D. (2006). Rafaél Gutiérrez Girardot: entre la crítica rigurosa y la diatriba desmedida. En Esbozos filosóficos I. De Inmanuel Kant a la crítica de la modernidad, 115-132. Bogotá: Produmedios.

Romero, J. L. (1999). Latinoamérica: las ciudades y las ideas. Medellín: Universidad de Antioquia. . (2001). Situaciones e ideologías en América Latina. Medellín: Universidad de Antioquia. . (2002). La Edad Media. México: Fondo de Cultura Económica. 